Purdue University Purdue e-Pubs

$3-1-2004$

\title{
Three-dimensional imaging of living and dying neurons with atomic force microscopy
}

\author{
Helen McNally \\ Purdue University, mcnallyh@purdue.edu \\ Richard B. Borgens \\ Purdue University, borgens@purdue.edu
}

Follow this and additional works at: http://docs.lib.purdue.edu/nanodocs

McNally, Helen and Borgens, Richard B., "Three-dimensional imaging of living and dying neurons with atomic force microscopy" (2004). Other Nanotechnology Publications. Paper 43.

http://docs.lib.purdue.edu/nanodocs/43

This document has been made available through Purdue e-Pubs, a service of the Purdue University Libraries. Please contact epubs@purdue.edu for additional information. 


\title{
Three-dimensional imaging of living and dying neurons with atomic force microscopy
}

\author{
HELEN A. MCNALLY ${ }^{1, *}$ and RICHARD BEN BORGENS ${ }^{1,2}$ \\ ${ }^{1}$ Center for Paralysis Research, School of Veterinary Medicine, Purdue University, West Lafayette, IN 47907-2096, USA; \\ ${ }^{2}$ School of Engineering, Purdue University, West Lafayette, IN 47907-2016, USA \\ monallyh@purdue.edu \\ cpr@purdue.edu
}

Received 23 December 2003; revised 10 February 2004; accepted 5 March 2004

\begin{abstract}
Atomic Force Microscopy (AFM) has been used to image the morphology of developing neurons and their processes. Additionally, AFM can physically interact with the cell under investigation in numerous ways. Here we use the AFM to both three-dimensionally image the neuron and to inflict a nano/micro-puncture to its membrane. Thus, the same instrument used as a tool to precisely penetrate/cut the membrane at the nanoscale level is employed to image the morphological responses to damage. These first high resolution AFM images of living chick dorsal root ganglion cells and cells of sympathetic ganglion and their growing processes provide confirmation of familiar morphologies. The increased resolution of the AFM revealed these structures to be significantly more complex and variable than anticipated. Moreover we describe novel, dynamic, and unreported architectures, particularly large dorsally projecting ridges, spines, and ribbons of cytoplasm that appear and disappear on the order of minutes. In addition, minute (ca. $100 \mathrm{~nm}$ ) hair-like extensions of membrane along the walls of nerve processes that also shift in shape and density, appearing and disappearing over periods of minutes were seen. We also provide "real time" images of the death of the neuron cell body after nano/micro scale damage to its membrane. These somas excreted their degraded cytoplasm, revealed as an enlarging pool beneath and around the cell. Conversely, identical injury, even repeated perforations and nanoslices, to the neurite's membrane do not lead to demise of the process. This experimental study not only provides unreported neurobiology and neurotrauma, but also emphasizes the unique versatility of AFM as an instrument that can (1) physically manipulate cells, (2) provide precise quantitative measurements of distance, surface area and volume at the nanoscale if required, (3) derive physiologically significant data such as membrane pressure and compliance, and (4) during the same period of study—provide unexcelled imaging of living samples.
\end{abstract}

\section{Introduction}

Since its inception in 1986 (Binnig et al., 1986), Atomic Force Microscopy (AFM) has provided unparalleled imaging of organic and inorganic materials (Engel et al., 1999; Lee, 2000), though evaluation of living biological materials has been relatively limited (Morris et al., 1999). The evaluation of living cells has concentrated on internal cellular organelles (Lal et al., 1995) or nanoscale features of the surface including gap junctions, ion channels and focal adhesions (Jena, 1997). These studies make good use of the versatility and enormous power of resolution afforded by this technology. On the other hand, three-dimensional evaluation of the overall architecture of living cells has received little systematic study. Specifically, images of neurons and their growing tips (growth cones) by AFM have not been re- ported. This is in spite of the fact that AFM provides increased power of magnification/resolution coupled to real-time imaging of living samples-capabilities not shared with any other single imaging modality. AFM also provides the investigator with an unequaled measurement capability for minute samples (Snyder \& White, 1992), permitting precise computation of surface areas, volumes, and linear distance.

Here we provide the first clear, high resolution three-dimensional images of living neurons derived from embryonic chick dorsal root ganglia (DRG) and sympathetic ganglia in vitro using a Digital Instruments Scanning Probe Microscope (see also Ricci et al., 2004; Figs. 1-4). Although neuronal morphology has been intensely studied for over a century (DeFelipe \&

* To whom correspondence should be addressed. 


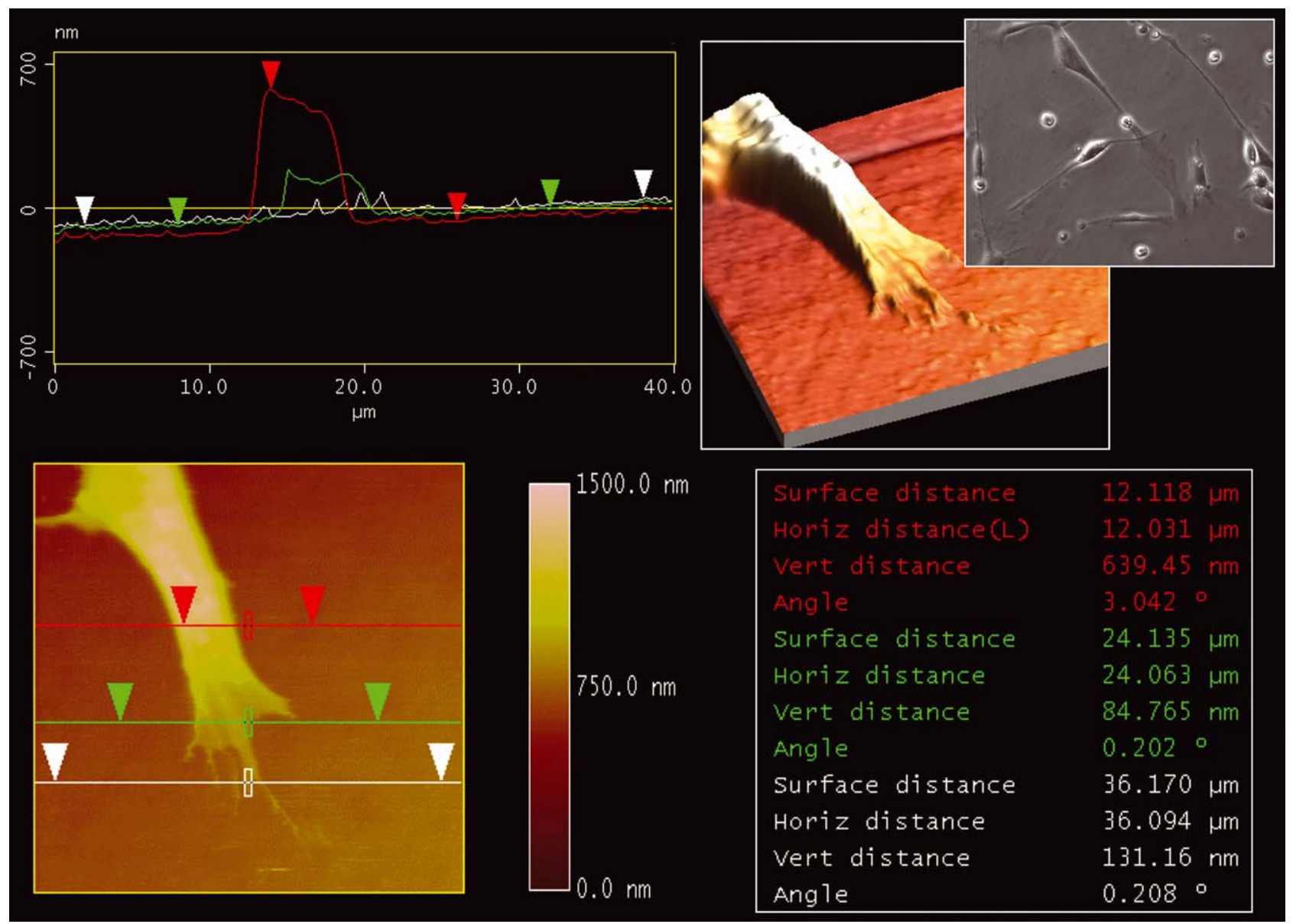

Fig. 1. AFM imaging and quantification of structure. The inset at the top right is a light micrograph taken previous to AFM imaging of cultured cells typical of those used for these studies (see Methods). Adjacent to it a single growth cone is shown after three-dimensional reconstruction, the "height mode" image of the same growth cone is shown at the bottom left. The color table to the right shows height in the $z$-axis. Note the three index lines crossing the growth cone (red, white, and green) scribed by the investigator. The actual height profile along these lines is provided in the graph above. The actual distance between the cursors is given in the table to the right of the growth cone. In addition to graphics, these quantitative capabilities are components of the AFM system.

Jones, 1988), the resolution of the AFM reveals new three-dimensional architectures suggesting novel functional characteristics as we discuss. In particular, we emphasize the dynamic, minute-by-minute assembly and disassembly of spines and "thorn-like" structures in the vertical axis of both the growth cone and soma, as well as fine hair-like extensions from the walls of neurites.

The AFM has also been employed to physically interact with the sample under investigation as a nanomanipulator for the mechanical movement of atoms (Eigler \& Schweizer, 1990), fabricating nanoelectronics (Piner et al., 1999), and for molecular force measurements (Colton et al., 1997) among others. In this study, we used the AFM to both: (1) make precise nano/micro punctures to the membranes of the nerve cell body (soma) and the terminal ends of growing neurites, and (2) subsequently image the same cell after withdrawing the AFM's nanoprobe from the surface.

\section{Methods and materials}

\section{SAMPLE ORIGIN, DISASSOCIATION, AND CULTURE}

Chick DRGs and sympathetic ganglia were dissected from $7 \frac{1}{2}-8$ day old chick embryos by conventional methods. Individual neurons were obtained from the tissue by conventional procedures involving trituration, enzymatic digestion (using trypsin in Puck's medium), and differential centrifugation. Cell suspensions were moved to $35 \mathrm{~mm}$ Petri dishes and cell density within these samples was monitored using a hemocytometer. For the purposes of this study we attempted to obtain primary cultures on the order of 40,000 cells/35 mm petri dish-plated on a substrate of polyornithine and laminin, and maintained at $37^{\circ} \mathrm{C}$ in $5 \% \mathrm{CO}_{2}$. Healthy DRG neurons on laminin, for example, will attach to the substrate and begin to form process within 24 hours.

A 2\% neuron growth medium (Ventimiglia \& Lindsay, 1998) containing nerve growth factor (NGF), vitamin C, insulin (Sigma Chem. Co., I-6634), and penicillin /streptomycin (Sigma Chem. Co., P-0906) was used in these studies. 

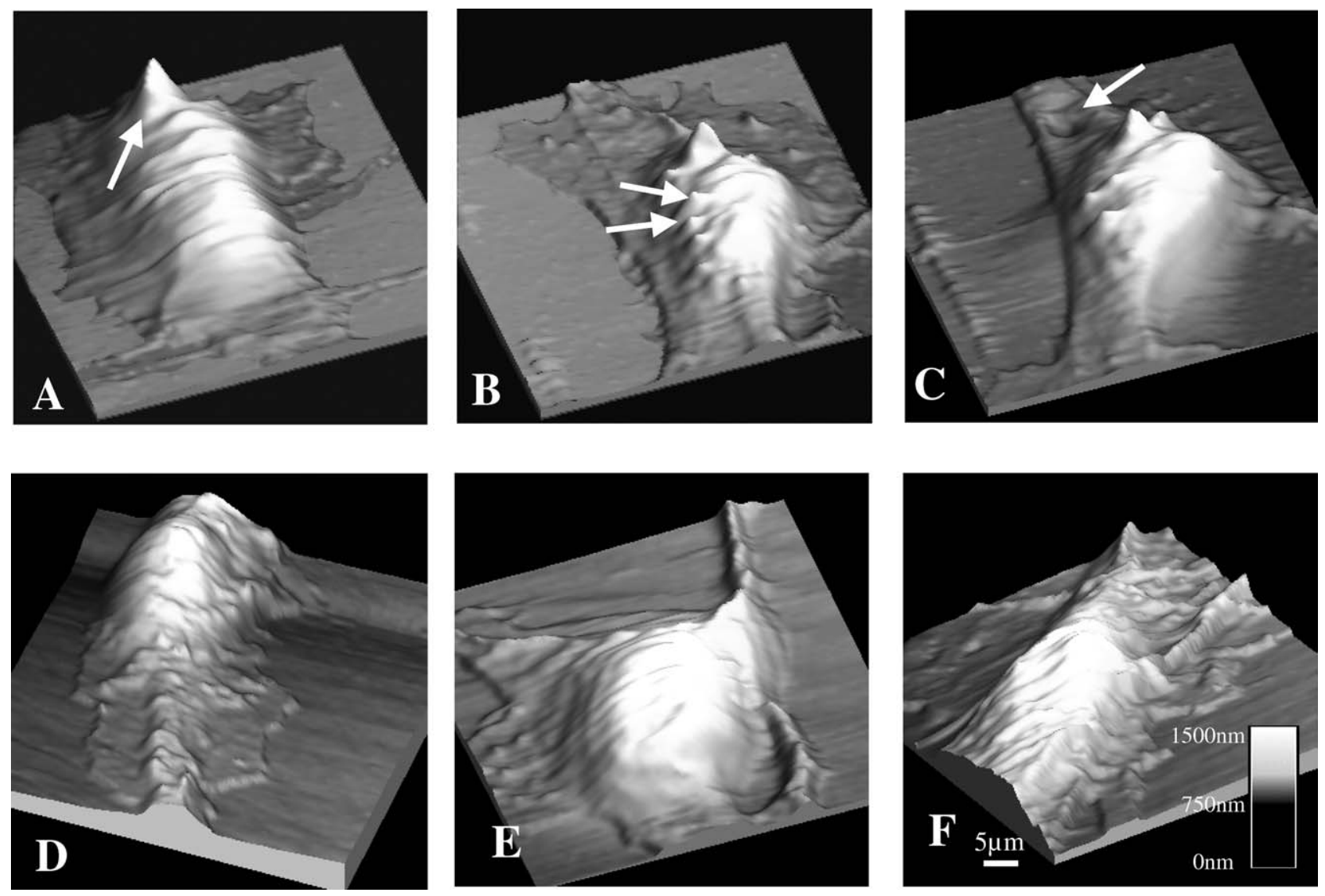

Fig. 2. Cell bodies of dorsal root ganglion cells. A, B, and C are three-dimensional reconstructions of a single DRG cell body. The images were acquired sequentially, each image taking approximately 30 minutes to obtain. The long neurite of this cell is out of the field of view, allowing resolution of the shape changes of the neuron's soma over this period of approximately 15 minutes. Note that the conformation of the soma does not only change over a period of minutes due to the lamellipodia extending over adjacent substrate (polyornithine/laminin)—but that the overall conformation of the entire cell body shifts in shape dramatically in all three dimensions. Noteworthy are the vertically projecting spines and ridges (arrows) that assemble and disassemble over this period. In $\mathrm{C}$, the lamellipodia of the neuron extend around a region of substrate forming a small hole within the boundary of the cell (arrow). This cavity extended completely through the cell—confirmed by comparing the three-dimensional reconstruction with both amplitude and height scans. D, E, and F are three-dimensional reconstructions of additional DRG cell bodies. Note though the cell shape is dramatically different in each case-all cells possess a domed and irregular soma surrounded by a flattened lamellipodia. The scale bar applies to X and Y dimensions and the color bar applies to the $\mathrm{Z}$ dimension. These are shown only in the $\mathrm{F}$ panel, but apply to all panels as the dimensions are very similar.

The base medium was prepared from an F-12 nutrient mixture (Gibco, 21700-075) supplemented with the other adjuncts including conalbumin (Sigma, C-0 880) and horse serum (Gibco, 26050-088) to a final $\mathrm{pH}$ of $\sim 7.4$, and refrigerated until used.

\section{AFM OF CULTURED NEURONS}

After culture dishes containing developing neurons were removed from incubation for evaluation with the AFM, temperature, humidity and $\mathrm{CO}_{2}$ levels were not controlled. Thus experiments never exceeded 4 hours, at which time cells were still healthy and well attached to the substrate. Cultured cells were rinsed with warmed media and covered with $2 \mathrm{ml}$ growth media. The samples were examined under a Nikon inverted microscope with $10 \times$ objective to choose viable cells at relatively low density where individual neurons and their processes would not be at confluence (inset in Fig. 1). Glass cover slips possessing a grid (Electron Microscopy Sciences, 72264-23) were used to return to the locations of interest when the sample was moved to the stage of the AFM. Well over 50 individual neurons ( 95\% DRG, 5\% sympathetic ganglion) were evaluated in this investigation, and the numbers of individual cells in various subsets where quantitative measurements were made is given in the Results section.

The sample was then imaged in tapping mode using a Digital Instruments Dimension 3100 AFM. The fluid cell (Digital Instruments, DTFML) was fitted with a silicon nitride tip (Digital Instruments, DNP-20). The cantilever was $\mathrm{V}$-shaped, $200 \mu \mathrm{m}$ in length yielding a nominal spring constant of $0.32 \mathrm{~N} / \mathrm{m}$. The tip was square pyramidal in shape with a nominal tip radius of curvature of $20-60 \mathrm{~nm}$. The laser was 

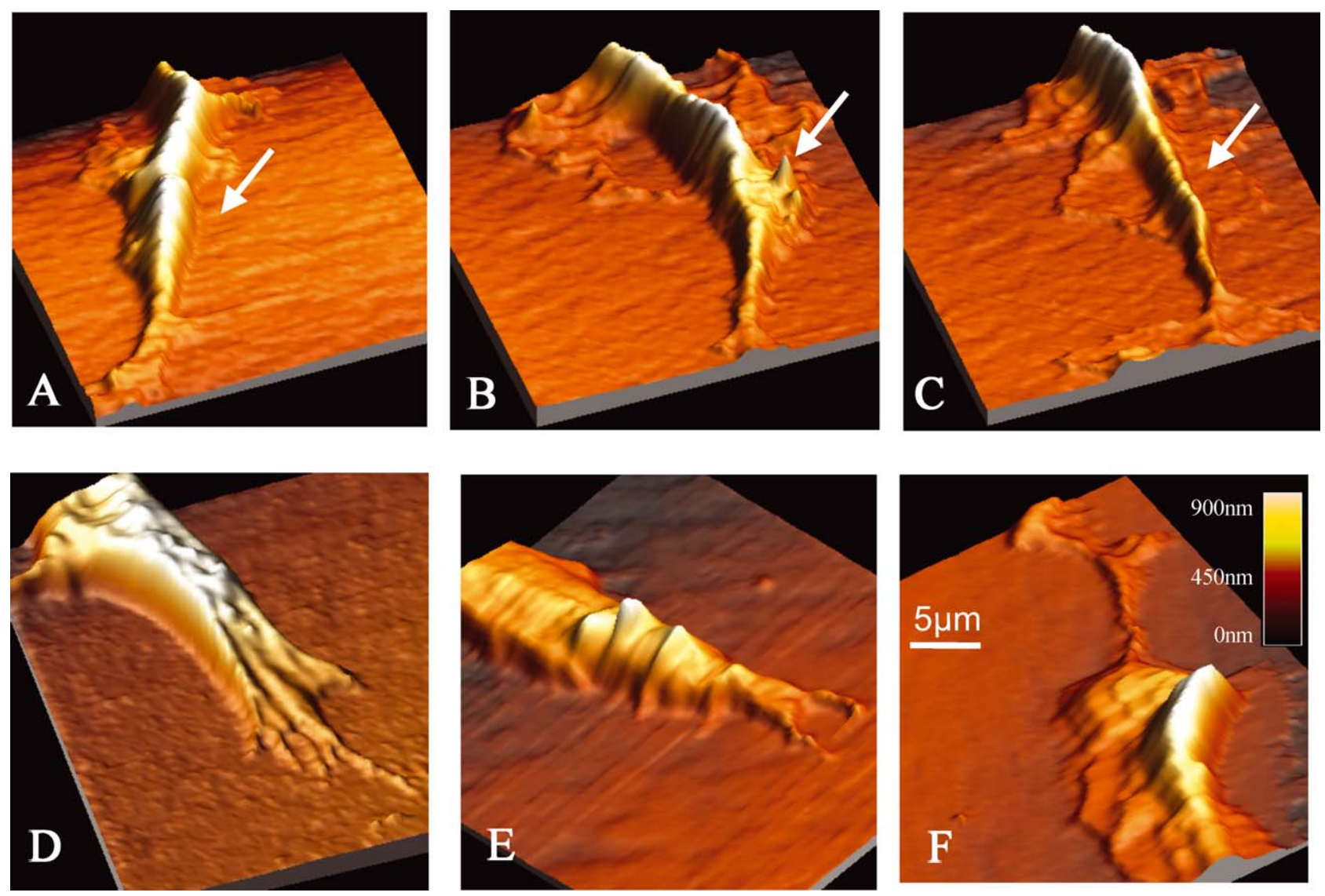

Fig. 3. Growing tips of dorsal root ganglion neurites. The three-dimensional shape of the growing tip of a single neurite is shown in $\mathrm{A}-\mathrm{C}$, images acquired approximately 5 minutes apart. While the rapid extension and retraction of cytoplasm extending horizontal to the plane of the substrate has been revealed by other imaging techniques in living cells, the relatively high ridges and more singular spines (depicted by arrow in B, but not in A \& C) which dynamically reshape themselves on the order of minutes have not. Panels D-F are three-dimensional reconstructions of additional sympathetic (D) and DRG (E, F) growth cones. Vertical projections as well as horizontal spines are present in each case and yet dramatically different. The scale bar applies to $\mathrm{X}$ and $\mathrm{Y}$ dimensions and the color bar applies to the $\mathrm{Z}$ dimension. These are shown only in the $\mathrm{F}$ panel, but apply to all panels as the dimensions are very similar.

aligned on top of the cantilever and adjustments of alignment made to the photo detector for maximum sensitivity. Course approach to the surface was performed until the fluid cell entered the culture medium. At that time, the alignment was adjusted and the resonance frequency determined $(6-8 \mathrm{kHz})$ for maximum tip oscillation. A drive amplitude of $4-600 \mathrm{mV}$ was applied to obtain a free amplitude of $0.5 \mathrm{~V}$ RMS. This was performed at $200 \mathrm{~nm}$ from the sample's surface. The tip was then brought into "contact" with the surface. Control parameters were optimized to apply minimal force on the sample. The set point parameter was increased until the tip lifted off the sample surface. The set point was then decreased by the smallest increment allowing for minimal force on the sample. Other parameters such as scan size, angle, rate and proportional \& integral gains were adjusted to optimize the image. The $256 \times 256$ data point image fields $\left(\sim 10 \mu \mathrm{m}^{2}\right)$ were obtained at $0.4-0.6 \mathrm{~Hz}$ per line, requiring $2-10$ minutes to complete a raster scan of the entire sample. The small unit area comprising a neurite or growth cone usually required 2 minutes prior to the next period of imaging while large cell bodies could take 5 to 10 minutes to image. Thus it is important to note that some features of the anatomy that may change within this time constant would not be a portion of the composite. Both height and amplitude modes were used to image the surface topography. Figure 1 shows a "height image" of a growth cone analyzed for quantitative profiles of interest, and reveals how any portion of a complete image can thus be quantitatively analyzed.

\section{NANOSLICE TECHNIQUE}

A precise nanoslice to the cell soma or growth cone membrane was performed to study the acute response of the cell to such an insult. A nanoslice was executed over the width of the cell/process by stopping the scan along the slow scan axis (y-direction), but continuing motion on the fast scan axis ( $x$ direction). The force applied to the cell surface by the AFM tip was increased until the height profile was reduced by one fifth of its original height. Typically the cells were 1-2 $\mu \mathrm{m}$ in height, thus the "slice" was approximately 200-400 nm in depth (completely penetrating the cell membrane). Since the scanner remained in one location along the $y$-axis as the 


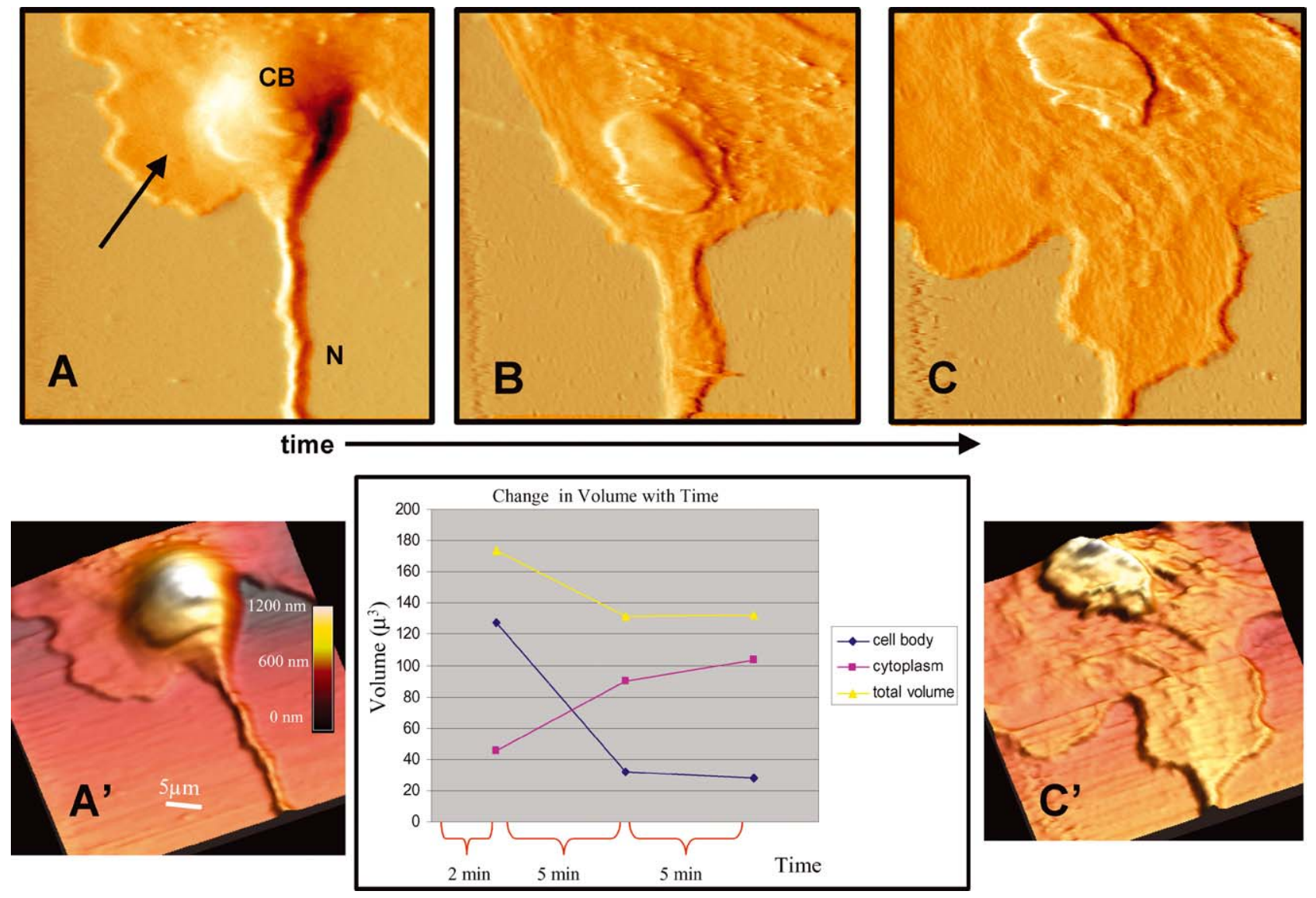

Fig. 4. Nerve cell death: A, B, and C show three different images of the same cell body and neurite imaged approximately 5 minutes apart using amplitude mode acquisition. Panel A was acquired approximately 2 minutes after a "microslice" of the dorsal membrane of the cell body was performed using the AFM probe tip. We estimate this cut to be $200 \mathrm{~nm}$ deep (penetrating completely through the membrane) and about $50 \mathrm{~nm}$ wide (refer to Methods). CB labels the cell body, $\mathbf{N}$ a single long neurite extending from it. Note a pool of cytoplasm beginning to form around the damaged neuron (arrow), although immediately after damage, the boundary between the liquefied cytoplasm and border of the intact cell was indistinct. In B and C, note that this pool enlarges and expands at each successive time of image acquisition coincident with the (i) collapse in height of the cell body and (ii) progressive expansion of the region of degradation into the neurite. Only a suggestion of the original contours of the cell remains (C) approximately 15 minutes after injury. The data plot provides estimates of the loss in cell body volume relative to that of the expansion of degenerate cell material above the surface of the substrate. The estimated total volume is also shown. Panels $\mathrm{A}^{\prime}$ and $\mathrm{C}^{\prime}$ are 3D reconstructions of the height data taken simultaneously with panels A and C. The scale bar applies to $\mathrm{X}$ and $\mathrm{Y}$ dimensions and the color bar applies to the $\mathrm{Z}$ dimension. The color bar only applies to the height mode images in panels $\mathrm{A}^{\prime}$ and $\mathrm{C}^{\prime}$.

tip penetrated the membrane, the width of the penetration was limited to one width of the tip, 20-60 nm nominally. The length of the nanoslice was $2-3 \mu \mathrm{ms}$.

\section{Results}

\section{THREE-DIMENSIONAL ARCHITECTURE OF NEURONS} IN VITRO

The common perception of the cell body of cultured neurons as a relatively smooth dome-shaped structure (sometimes adorned with spines) surrounded by an active lamellipodia and ruffled membrane requires revision. The AFM revealed the cell body to possess a very complex topography consisting of ridges, folds, and "thorns" and "spines" of varying lengths and diameters projecting even vertically from the cell surface for distances up to $1 \mu \mathrm{m}$. After attachment to the substrate, the somas of individual chick DRG neurons were on the order of $10 \times 20 \mu \mathrm{m}$ (minor vs. major axis of ellipsoid) in diameter-the cell body extending approximately 1-4 $\mu \mathrm{m}$ above the substrate. Spiny projections and steep ridges project an additional $200 \mathrm{~nm}$ above the surface of the lamellipodia and $1 \mu \mathrm{m}$ from the central mass of the cell body. Moreover these complex shapes are not characteristic of an individual cell under scrutiny as they constantly shift from one form to another over a period of minutes (Fig. 2; one AFM raster scan of an entire cell body takes approximately 10 minutes, 
and less than half this time to scan a neurite's terminal and growth cone). Therefore, the three-dimensional cytoarchitecture of microfilaments and microtubules subtending these complex shapes are in dynamic stages of assembly and disassembly on a minute-by-minute basis as generally believed. A similar picture emerged for growth cones. Although their continuous change in two-dimensional form was expected, we were surprised by the relatively tall ridges and thorn-like projections in the vertical axis. Likewise, these thorns and sharp protuberances were a continuously changing feature of the elongating tip, often associated with a ridgelike or "thorny backbone" extending into the growth cone proper (Fig. 3). The terminal ends of neurites averaged $6.0 \pm 2.1 \mu \mathrm{m}$ wide and $385.1 \pm 192.7 \mathrm{~nm}$ high $(n=15)$. The vertical ridges and spines were commonly observed throughout the length of the elongating neurite averaging $94.9 \pm 70.2 \mathrm{~nm}$. The area of growth cones averaged $10.3 \pm 2.9 \mu \mathrm{m}$ wide and $260.4 \pm 176.0 \mathrm{~nm}$ high with vertical projections averaging $258.5 \pm 148.6 \mathrm{~nm}$ $(n=15)$.

In addition to 3-D imaging of the filopodia and microspikes of the growing tip, the AFM resolved fine structures projecting from the sides-or lateral walls-of nerve fibers. These often dense hair-like projections were perpendicular to the long axis of the neurite, and were often observed along the entire length of the fiber. Individual "hairs" ranged in caliber from $100 \mathrm{~nm}$ to $1 \mu \mathrm{m}$, and were on the order of $200 \mathrm{~nm}$ in length extending from their "base" at the neurite's membrane. Similar to the relatively massive ridges and spines, these minute structures also extended and retracted continuously between scans-changing shape, or disappearing all together. Finally, we did not see any evidence of an equilibrium stage of cell architecture where all-or even most-of these topographical features remained static.

With certainty, DRG cells in vitro are dynamic shape-shifting entities. These characteristics are common to both DRG and sympathetic neurons suggesting even the striking dorsal projections and ridges are likely general characteristics of developing neurons in vivo.

\section{DEATH OF THE NEURON IN RESPONSE TO}

\section{MECHANICAL BREACH OF ITS MEMBRANE}

Precise nano/micropuncture of the living cell membrane can be made with the tip of the AFM in "tapping mode". Previously, insult to the cell membrane or dissection of cells has been performed in "contact mode" (Lal et al., 1995). We used tapping mode to just penetrate the cell membrane, subsequently withdrawing the probe to perform imaging. Typically, penetration of the membrane of the cell body to a depth of 100-200 nm, over a distance of 2-3 $\mu \mathrm{m}$ produced a rapid collapse of the cell body within $\sim 20$ minutes. The death of the neuron in response to this "nanoslice" (20-60 nm in width) was observed to occur in an identical fashion in over a dozen individual tests.

Immediately after membrane puncture, the cell began to spill its cytoplasm onto the substrate, forming an enlarging pool. Thus, the liquid pool that formed around the punctured neuron was of a higher specific gravity than the extracellular medium, and unlikely to be simply cytoplasm as we discuss below. In every case, this extracellular pool enlarged coincident with the collapse of the punctured cell body. This is shown in Figure 4, the initial height of the soma was determined to be $1.5 \mu \mathrm{m}$ and plummeted to $0.3 \mu \mathrm{m}$ in just over 15 minutes. The volume of the cell body was reduced from $127.6 \mu \mathrm{m}^{3}$ to $28.2 \mu \mathrm{m}^{3}$ as the volume of the pool of extruded material increased from $45.8 \mu \mathrm{m}^{3}$ to $103.8 \mu \mathrm{m}^{3}$ over this same period of time. The calculation of the volume of extruded cytoplasm are actually underestimated since the enlarging liquid pool extended past the field of view in some images. With time after injury, compromise of the membrane spread progressively across the soma from the minute and local puncture, eventually degrading even the proximal neurites (Fig. 4c).

\section{Discussion}

Few of the three-dimensional features discussed in this text have been reported in any single cell to our knowledge. This includes recent texts (Vale et al., 1992; Ventimiglia \& Lindsay, 1998), reports (Lemmon et al., 1992; Stoeckli et al., 1996; Suter \& Forscher, 2000), and even professional rendered image galleries available on the World Wide Web (for example, www.visualsunlimited.com). This fact was particularly curious when reviewing neuron or growth cone form obtained by Scanning Electron Microscopy (SEM), an instrument capable of similar powers of resolution-but only on dead samples (for example, Fig. 1, page 263 in citation Vale et al., 1992). Evidence of the dynamic activity of neurons and their growing processes have been provided in modern times by many different imaging techniques including 3-D Confocal Imaging and Differential Interference Contrast Microscopy. Neither of these imaging methods, however, provide both "real time" capture of images from living cells in addition to nanoscale resolution. The AFM provides this capability, though as discussed earlier, has been infrequently employed for such investigation of whole cells, and even more rarely for cells of the nervous system. We note only one report using a transformed cell type, the PC-12 cell (Lal et al., 1995). PC-12 cells are often used as a model for neurons in vitro, though these cells are not native neurons. This particular report focused on actin arrays in lamellipodia and did not evaluate the gross structure of the cells, their neurites, or their overall activity-a characteristic of this emerging literature using AFM. Moreover, AFM 
evaluation of cell form permits precise imaging of a biological sample in all dimensions-particularly in the $Z$ axis. Actually, AFM provides its most precise quantification of structure in the $z$-axis $(0.1 \mathrm{~nm})$ due to the extreme sensitivity of the cantilever employed and the beam bounce detection method (Meyer \& Amer, 1988).

\section{THOUGHTS ON WHAT THE NOVEL}

THREE-DIMENSIONAL ARCHITECTURE SUGGESTS ABOUT NEURONAL FUNCTION

The Soma's curious ridges, spines, and ribbons of membrane-bound cytoplasm are not likely to be anatomically analogous to the spreading and retracting lamellipodia/filopodia/microspike structures. In the latter, substrate attachment by membrane spanning proteins (often forming linkages to the cytoskeleton), cell adhesion molecules, and specialized receptors provide stability to both the cell body and the terminal end of the neurite where and when focal adhesion is successful. The architectures projecting upwards above the cell are not provided such stabilizing factors associated with the substrate. Thus, the entire scaffolding of cytoskeleton supporting the vertical projections must be born by the cell at an enormous cost in energy as these structures are assembled and disassembled continuously.

In the growth cone however, the dorsal spines and ridges may be functionally analogous to the better understood filapodial extensions and microspikes. These latter extensions of the growing tip are replete with specialized receptors for various neurotrophic, neurotropic, and cell adhesion factors important in cell motility and guidance (Harris, 1986; Bray, 1992). It is reasonable to suggest the cytoplasmic projections of membranes extending into the extracellular milieu "above" the cell may possess the receptor machinery to sample soluble neurotropic factors. It is less obvious what the functional importance of similar structures characteristic of the soma may be-perhaps ridges and spines may be anlagen of dendritic projections that are not stable in the absence of cell-to-cell connections.

\section{ACUTE CELL DEATH AFTER MECHANICAL DAMAGE} TO THE MEMBRANE

The failure of membrane sealing after such a relatively minute wound to the perikaryon was surprising, and may require revision of our understanding of acute neuronal (cellular) sealing and repair. Orthodoxy suggests the cell membrane does not support open breaches, actual "holes", after minor damage. This is the lesson of microelectrode impalation of cells, and the literature of electroporation and biolistics. The sol/gel of the membrane is seen more as "jelly" than "skin", and the "breaches" in it that allow uptake or loss of molecular labels after damage are conceived of as localized regions where membrane permeability has been compromised, not where actual "holes" in the membrane persist (Dimitrov \& Jaine, 1984; Schwister \& Deutike, 1985). Here we show that a small puncture on the order of $<3 \mu \mathrm{m}$ in extent, ca. hundreds of nm deep, and $20-60 \mathrm{~nm}$ in width can indeed destroy the cell. However, similar punctures to the membrane of the terminal end of the neurite, including the growth cone, did not lead to cell death. Even repeated punctures, up to four within 5 minutes, were apparently repaired by endogenous sealing. Not one neurite of the 10 tested was compromised by such repeated damage (data not shown). The explanation for this difference is not at hand, but is in keeping with other reports defining the robust nature of axons in CNS white matter. Axons are not only resistant to mechanical damage, but are also very tolerant of prolonged and significant periods of oxygen and glucose deprivation (Peasley \& Shi, 2002).

We also point out that the liquefied cytoplasm is of a different construct than normal. The rise in intracellular $\mathrm{Ca}^{++}$and $\mathrm{Na}^{+}$concentrations subsequent to the membrane breach in particular would lead to a catastrophic degradation of the cytoskeleton and an increase in the fluidity of the cytosol. Still, this material is "heavier" than the aqueous media into which it spills. It maintains itself as a pool spreading out on the floor of the culture chamber. We did not follow this process for longer than $\frac{1}{2}$ hour-at this time the contents of the cell were still visible around it, and not yet dissolved into the culture medium.

\section{Conclusions}

After a decade of use, the AFM is still underutilized in studies of living cells at all ranges of magnification and resolution. The bulk of investigation to date has been at the very high magnification/resolution afforded by AFM, and on fixed samples. While designed for probing nanostructure, we show that the AFM is not only an ideal tool for investigating general cell morphology, but additionally its various modes of operation (contact, non-contact, tapping, and various scanning regimens) that physically interact with cells under investigation can be harnessed for novel experimentation. The versatility of the AFM also provides for the measurement of additional physical properties (pressure, capacitance) of the membrane and subcellular components and cell responses to external stimuli. Our continuing studies will focus on issues of nerve membrane repair. Particularly the administration of inorganic polymers applied to injured nervous tissue which strikingly facilitate membrane sealing and reassembly. Often, application of these polymers rescues cells doomed to die, and in general leads to immediate (minutes) recovery of nerve conduction and function (Shi \& Borgens, 1999, 2000). The mechanisms of action underlying polymer-mediated rescue and repair is far from clear (Borgens, 2001, 2003). The AFM 
will allow us to probe the behavior of polymers like polyethylene glycol (Borgens et al., 2002) and Poloxamer 188 (Borgens et al., 2004) with damaged nerve membranes by directly observing the molecules interaction with the membrane rupture while quantitatively monitoring relevant characteristics such as changes in membrane pressure in contact mode during the repair process. In short, the application of AFM to studies of neurobiology has "barely scratched the surface".

\section{Acknowledgments}

We gratefully acknowledge the technical assistance of Ms. Judy Grimmer, Cell Culture Lab, Center for Paralysis Research (CPR), Purdue University. We also thank Professor Michael Melloch, Purdue University, for access to the AFM used in this study. We would also like to thank Drs. Christopher Chen, Daniel Suter and Peter Lansbury for their expert opinions and discussions concerning these images. This work was supported by CPR general funds and HB1244 from the State of Indiana.

\section{References}

BINNIG, G., QUATE, C. F. \& GERBER, C. (1986) Atomic Force Microscope. Physical Review Letters 56, 930-933.

BORGENS, R. B. (2001) Cellular engineering: Molecular repair of membranes to rescue cells of the damaged nervous system. Neurosurgery 49, 370-378; discussion 378-379.

BORGENS, R. B. (2003) Restoring Function to the Injured Human Spinal Cord. Heidelberg: Springer-Verlag.

BORGENS, R. B., SHI, R. \& BOHNERT, D. (2002) Behavioral recovery from spinal cord injury following delayed application of polyethylene glycol. Journal of Experimental Biology 205, 1-12.

BORGENS, R. B., BOHNERT, D., DUERSTOCK, B., SPOMAR, D. \& LEE, R. (2004) A subcutaneous tri-block copolymer produces recovery from spinal cord injury. Journal of Neuroscience Research 76, 141-154.

BRAY, D. (1992) Cell Movements. New York, NY: Garland Publishing, Inc.

COLTON, R. J., BASELT, D. R., DUFRENE, Y. F., GREEN, J. B. \& LEE, G. U. (1997) Scanning probe microscopy. Current Opinion in Chemical Biology 1, 370-377.

DEFELIPE, J. \& JONES, E. G. (1988) Cajal on the Cerebral Cortex. London, UK: Oxford University Press.

DIMITROV, D. \& JAINE, R. K. (1984) Membrane stability. Biochimica et Biopysica Acta 779, 437-468.

EIGLER, D.M. \& SCHWEIZER, E. K. (1990) Positioning single atoms with a scanning tunneling microscope. Nature 344, 524-526.

ENGEL, A., LYUBCHENKO, Y. \& MULLER, D. (1999) Atomic force microscopy: A powerful tool to observe biomolecules at work. Trends in Cell Biology 9, 77-80.

JENA, B. (1997) Providing new insights in the structure and function of living cells. Cell Biology International 21, 683-684.

HARRIS, W. A. (1986) Homing behaviour of axons in the embryonic vertebrate brain. Nature 320, 266-269.
LAL, R., DRAKE, B., BLUMBERG, D., SANER, D. R., HANSMA, P. K. \& FEINSTEIN, S. C. (1995) Imaging real-time neurite outgrowth and cytoskeletal reorganization with an atomic force microscope. American Journal of Physiology 269, C275-C285.

LEE, T. (2000) Electronic properties of metallic nanoclusters on semiconductor surfaces: Implications for nonelectronic device applications. Journal of Nanoparticle Research 2, 345-362.

LEMMON, V., BURDEN, S. M., PAYNE, H. R., ELMSLIE, G. J. \& HLAVIN, M. L. (1992) Neurite growth on different substrates: Permissive versus instructive influences and the role of adhesive strength. Journal of Neuroscience $12,818-826$.

MEYER, G. \& AMER, N. A. (1988) Novel optical approach to atomic force microscopy. Applied Physics Letters 53, 2400-2402.

MORRIS, V. J., KIRBY, A. R. \& GUNNING, A. P. (1999) Atomic Force Microscopy for Biologists. Norwich, UK: Imperial College Press.

PEASLEY, M. A. \& SHI, R. (2002) Resistance of isolated mammalian spinal cord white matter to oxygen-glucose deprivation. American Journal of Physiology-Cell Physiology 283, C980-C989.

PINER, R. D., ZHU, J., XU, F., HONG, S. \& MIRKIN, C. A. (1999) "Dip-Pen" nanolithography. Science 283, 661-663.

RICCI, D., GRATTAROLA, M. \& TEDESCO, M. (2004) Growth Cones of Living Neurons Probed by Atomic Force Microscopy (edited by BRAGA, P. C. \& RICCI, D.) p. 125. Totowa, NJ: Humana Press Inc.

SCHWISTER, K. \& DEUTIKE, B. (1985) Formation and properties of aqueous leaks induced in human erythrocytes by electrical breakdown. Biochimica et Biopysica Acta 816, 332-348.

SHI, R. \& BORGENS, R. B. (1999) Acute repair of crushed guinea pig spinal cord by polyethylene glycol. Journal of Neurophysiology 81, 2406-2414.

SHI, R. \& BORGENS, R. B. (2000) Anatomical repair of nerve membranes in crushed mammalian spinal cord with Polyethylene Glycol. Journal of Neurocytology 29, 633-644.

SNYDER, S. R. \& WHITE, H. S. (1992) Scanning tunneling microscopy, atomic force microscopy, and related techniques. Analytical Chemistry 64, 116R-133R.

STOECKLI, E. T., ZIEGLER, U., BLEIKER, A. J., GROSCURTH, P. \& SONDEREGGER, P. (1996) Clustering and functional cooperation of $\mathrm{Ng}-\mathrm{CAM}$ and axonin-1 in the substratum-contact area of growth cones. Developmental Biology 177, 15-29.

SUTER, D. M. \& FORSCHER, P. (2000) SubstrateCytoskeletal coupling as a mechanism for the regulation of growth cone motility and guidance. Journal of Neurobiology 44, 97-113.

VALE, R. D., BANKER, G. \& HALL, Z. W. (1992) An Introduction to Molecular Neurobiology (edited by HALL, Z. W.) p. 263. Massachusetts: Sinauer Associates, Inc.

VENTIMIGLIA, R. \& LINDSAY, R. M. (1998) Rat striatal neurons in low-density, serum-free culture. In: $\mathrm{Cul}$ turing Nerve Cells, 2nd edition (edited by BANKER, G. \& GOSLIN, K.) p. 391. Massachusetts: The MIT Press. 